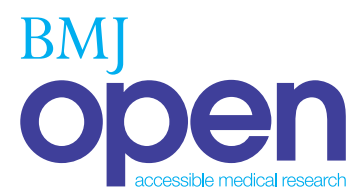

\title{
The safety and efficacy of intracoronary nitrite infusion during acute myocardial infarction (NITRITE-AMI): study protocol of a randomised controlled trial
}

\author{
D A Jones, ${ }^{1,2}$ M Andiapen, ${ }^{2}$ T J A Van-Eijl, ${ }^{1}$ A J Webb, ${ }^{1}$ S Antoniou, ${ }^{2}$ \\ R J Schilling, ${ }^{1,2}$ A Ahluwalia, ${ }^{1}$ A Mathur ${ }^{1,2}$
}

To cite: Jones DA, Andiapen M, Van-Eijl TJA, et al. The safety and efficacy of intracoronary nitrite infusion during acute myocardial infarction (NITRITE-AMI): study protocol of a randomised controlled trial. BMJ Open 2013;3:e002813.

doi:10.1136/bmjopen-2013002813

- Prepublication history for this paper are available online. To view these files please visit the journal online (http://dx.doi.org/10.1136/ bmjopen-2013-002813).

Received 28 February 2013 Accepted 4 March 2013

This final article is available for use under the terms of the Creative Commons Attribution Non-Commercial 2.0 Licence; see http://bmjopen.bmj.com

${ }^{1}$ Centre of Clinical Pharmacology, Barts NIHR Cardiovascular Biomedical Research Unit, William Harvey Research Institute, Queen Mary University, London, UK

${ }^{2}$ Department of Cardiology, London Chest Hospital, Barts Health NHS Trust, London, UK

Correspondence to Dr D A Jones; danieljones@doctors.org.uk

\section{ABSTRACT}

Introduction: Acute myocardial infarction (AMI) is a major cause of death and disability in the UK and worldwide. Presently, timely and effective reperfusion with primary percutaneous coronary intervention (PPCl) remains the most effective treatment strategy for limiting infarct size, preserving left ventricular ejection fraction (LVEF) and improving clinical outcomes. However, the process of reperfusion can itself induce cardiomyocyte death, known as myocardial reperfusion injury, for which there is currently no effective therapy. Extensive preclinical evidence exists to suggest that sodium nitrite (as a source of endogenous nitric oxide) is an effective therapeutic strategy for preventing myocardial reperfusion injury. The purpose of NITRITE-AMI is to test whether sodium nitrite reduces reperfusion injury and subsequent infarct size in patients undergoing PPCl for MI.

Methods and design: NITRITE-AMI is a doubleblind, randomised, single-centre, placebo-controlled trial to determine whether intracoronary nitrite injection reduces infarct size in patients with myocardial infarction undergoing primary angioplasty. The study will enrol 80 patients presenting with ST-elevation myocardial infarction. Patients will be randomised to receive either a bolus of intracoronary sodium nitrite or placebo (sodium chloride) at the time of PPCI. The primary outcome is infarct size assessed by creatine kinase area under the curve (AUC) over $48 \mathrm{~h}$. Secondary endpoints include troponin T AUC and infarct size, LV dimensions and myocardial salvage index assessed by cardiac MR (CMR), markers of platelet reactivity and inflammation, the safety and tolerability of intracoronary nitrite, and 1 year major adverse cardiac events.

Ethics and dissemination: The study is approved by the local ethics committee (NRES Committee London West London: 11/L0/1500) and by the Medicines and Healthcare Products Regulatory Agency (MHRA) (EudraCT nr. 2010-022460-12). The results of the trial will be published according to the CONSORT statement and will be presented at conferences and reported in peer-reviewed journals.

Trial registration: United Kingdom Clinical Research Network (Study ID 12117), http://clinicaltrials.gov

\section{ARTICLE SUMMARY}

Article focus

- This article describes the study protocol of the first-in-man study assessing the safety and efficacy of intracoronary nitrite infusion during primary percutaneous coronary intervention (PPCI) for acute myocardial infarction (AMI) in a randomised double-blind placebo-controlled trial.

Key messages

- Despite the introduction of PPCl for treatment of AMI significant morbidity and mortality rates remain, mainly because of reperfusion injury contributing to infarct size.

- Reducing reperfusion injury is a major target in improving these outcomes.

- There is extensive preclinical data demonstrating efficacy of sodium nitrite (delivered locally) in reducing reperfusion injury and subsequent infarct size.

Strengths and limitations of the study

- This is the first randomised-controlled trial assessing the use of intracoronary nitrite to reduce infarct size during $\mathrm{PPCl}$ for ST-elevation myocardial infarction.

- It is a single-centre study, which can affect applicability of the results to other units.

(NCT01584453) and Current Controlled Trials (ISRCTN:38736987).

\section{INTRODUCTION}

Coronary heart disease is the commonest cause of death in the UK, as a consequence of acute myocardial infarction (AMI) causing 1 in 5 and 1 in 7 deaths in men and women, respectively (http://www.heartstats. org). Presently, timely and effective reperfusion with primary percutaneous coronary 
intervention (PPCI) for ST-elevation myocardial infarction (STEMI) remains the most effective treatment strategy for reducing myocardial infarct (MI) size, preserving left ventricular ejection fraction (LVEF) and preventing the onset of heart failure. ${ }^{1-4}$ However, despite the introduction of PPCI, and other advances such as the introduction of antiplatelet therapies, resulting in a reduction in mortality of $\sim 50 \%$ at 30 days, substantial mortality and morbidity rates still persist. ${ }^{56}$ The mortality of STEMI patients at 30 days undergoing PPCI in Europe remains significant (3-7\% in-hospital mortality depending on the country) ${ }^{7}$ and $15-20 \%$ of patients progress to develop heart failure. ${ }^{8}$ One of the main determinants of prognosis after AMI is the size of the infarct, ${ }^{9-11}$ and importantly increased infarct size is associated with an increased incidence of heart failure and arrhythmias. ${ }^{12-14}$ Thus, there is a clear need for identification of additional strategies that might decrease infarct size and improve outcome.

\section{REPERFUSION INJURY AND INFARCT SIZE}

In the setting of STEMI the immediate reopening of acutely occluded coronary arteries via PPCI is the treatment of choice to salvage the ischaemic myocardium. However, the sudden reinitiation of blood flow leads to a local acute inflammatory response with further endothelial and myocardial damage. This phenomenon, described as 'reperfusion injury' ${ }^{15}$ may explain why, despite optimum myocardial reperfusion, the shortterm mortality after AMI approaches $7 \%^{6}$ and the incidence of heart failure approaches $15-20 \% .{ }^{1}{ }^{14}$ Experimental in vivo models suggest that while $50 \%$ of the final infarct size is because of the ischaemic insult the remaining $50 \%$ is because of reperfusion injury. ${ }^{16}$ Although, the process of myocardial reperfusion continues to be optimised with recent advances in PPCI technology (thrombus aspiration, novel stents), ${ }^{17}$ antiplatelet (prasugrel, ticagrelor) ${ }^{18}$ and antithrombotic therapy (bivalirudin) ${ }^{19}$ there is currently no effective therapy for reducing myocardial ischaemia-reperfusion (I/R) injury per se.

\section{REDUCING REPERFUSION INJURY}

Disappointingly, while several strategies are effective in reducing $\mathrm{I} / \mathrm{R}$ injury in preclinical models the majority of these approaches have not translated to the clinical setting, with the notable exception of cyclosporine. ${ }^{20}$ However, more recently a potential solution to the problem of reperfusion injury has been proposed in the form of inorganic nitrite $\left(\mathrm{NO}_{2}^{-}\right)$. Over the last decade evidence has accumulated supporting the view that $\mathrm{NO}_{2}^{-}$, which is abundant in blood and tissues, ${ }^{21-24}$ represents a significant stable intravascular endocrine reservoir and tissue storage form of nitric oxide $(\mathrm{NO})$ that exerts a number of beneficial effects. ${ }^{25}$

\section{INORGANIC NITRITE}

Under normal conditions, basal endogenously generated $\mathrm{NO}$, produced via the conventional l-arginine/ $\mathrm{NO}$ synthase (NOS) pathway is essential for maintaining homeostasis, particularly, by sustaining normal healthy cardiac function, perfusion and cardioprotection. ${ }^{26} 27$ However, during ischaemia the activity of the predominant isoform that underlies this NO synthesis, that is, endothelial nitric oxide synthase (eNOS), is severely attenuated as a result of inadequate delivery of oxygen and cofactors. ${ }^{28}$ In addition, reperfusion generates oxidative stress, which also further reduces the bioavailability of $\mathrm{NO},{ }^{29}{ }^{30}$ thereby removing its cardioprotective effects. The cardioprotective effects of NO have been proposed to relate to a number of actions that combine to provide an overall beneficial profile. First, NO exerts potent vasodilator effects in the ischaemic myocardium, ${ }^{31}$ which allows for essential perfusion of injured tissue. In addition NO exerts antiinflammatory effects inhibiting leucocyte recruitment ${ }^{32} 33$ and thus suppressing the inflammatory cell-driven injury to the endothelium and perivascular myocardium that plays a major role in determining infarct size postmyocardial $\mathrm{I} / \mathrm{R}$ injury. ${ }^{34} \mathrm{NO}$ also exerts antiplatelet effects, which together with the antileukocyte actions of $\mathrm{NO}$ attenuates capillary plugging. ${ }^{35}$ Finally, deficient NO generation contributes to the delay in reendothelialisation following PPCI, enhances cardiomyocyte death and apoptosis during $\mathrm{I} / \mathrm{R}$ injury, and in the long term contributes to cardiomyocyte hypertrophy postinfarct and decreases the impact of strategies that might facilitate new cardiomyocyte generation. ${ }^{36} \quad 37$ Together, such preclinical observations are consistent with a protective role for $\mathrm{NO}^{35}$ and support the concept of pharmacotherapy focused on replacing the protective NO 'lost' during myocardial I/R injury.

\section{PRECLINICAL EVIDENCE FOR BENEFICIAL EFFECTS OF NITRITE}

$\mathrm{NO}_{2}^{-}$has now been shown to mediate a number of beneficial effects on the cardiovascular system. Perhaps the most potent and reproducible effect of $\mathrm{NO}_{2}^{-}$being its ability to mediate cytoprotection after $\mathrm{I} / \mathrm{R}$ in a number of organs and species. ${ }^{38-42}$ The activity of nitrite resides in its propensity for conversion to NO: the optimal conditions for which are low $\mathrm{p}_{2}$ and low $\mathrm{pH}$ conditions which prevail during ischaemic episodes and coincide with substantial reduction of NOS function. ${ }^{28}$ Studies from our own lab ${ }^{38}$ and those of others have demonstrated nitrite-derived NO production in the heart and blood vessels. ${ }^{22-24}$

The beneficial effects of inorganic nitrite on the heart were first demonstrated in $2004^{38}$ when administration of $\mathrm{NO}_{2}^{-}$either prior to or at reperfusion in the isolated rat Langendorff heart preparation improved both left ventricular function and coronary perfusion pressure as well as decreasing infarct size following an $\mathrm{I} / \mathrm{R}$ insult. 
Several studies followed confirming these beneficial effects on the heart demonstrating the protective effects of nitrite administered intraventricular or intracoronary in rodent models of AMI in vitro and in vivo. ${ }^{38} 394344$ Importantly, studies have confirmed that ischaemiadependent conversion of $\mathrm{NO}_{2}^{-}$to protective $\mathrm{NO}$ is also a property shared by human heart tissue ex vivo. ${ }^{38}$ The functional benefits of $\mathrm{NO}_{2}^{-}$have been translated to larger species in vivo, where the intravenous administration of $\mathrm{NO}_{2}^{-}$in just the last $5 \mathrm{~min}$ of a $2 \mathrm{~h}$ period of ischaemia in the heart, reduced infarct size by $\sim 50 \%$ as in dogs. ${ }^{45}$ Although, the largest body of evidence demonstrating the cytoprotective properties of $\mathrm{NO}_{2}^{-}$has accumulated in models of MI, similar protective effects have been evidenced in other organs subject to $I / R$ injury including the liver, ${ }^{39}$ brain $^{40}$ and kidney. ${ }^{42}$ In all of these studies the beneficial effects were shown to be because of the activity of NO and were specifically associated with the local application into or on the organ of interest.

These observations clearly support investigation of the potential of $\mathrm{NO}_{2}^{-}$in the treatment of acute STEMI, particularly where $\mathrm{NO}_{2}^{-}$could be delivered locally before balloon inflation at the time of PPCI. The design of this study seeks to determine whether a significant improvement in infarct size and clinical outcomes can be achieved by the intracoronary injection of nitrite during PPCI.

\section{METHODS AND ANALYSIS \\ Study design}

NITRITE-AMI is a double-blind, randomised, singlecentre, placebo-controlled trial to determine whether nitrite injection reduces infarct size in patients with myocardial infarction undergoing primary angioplasty (figure 1).

\section{Aims}

1. To assess whether intracoronary nitrite is safe, tolerable and reduces infarct size during PPCI in patients with AMI.

2. To understand the effect of intracoronary nitrite on inflammatory load and platelet function during PPCI for AMI.

Hypothesis: In patients with STEMI undergoing PPCI, an intracoronary injection of nitrite initiated prior to establishment of full reperfusion reduces infarct size through prevention of $\mathrm{I} / \mathrm{R}$ injury.

\section{Study participants}

This is a single-centre trial with 80 patients to be recruited at The Barts Health Heart Attack Centre, based at The London Chest Hospital. This centre runs a 24/7 heart attack care service covering a population of almost two million from the City of London to the M25 and performed 755 primary angioplasties in 2012. Haemodynamically stable patients aged between 18 and 80, presenting with STEMI, with a single culprit vessel will be recruited. Potentially eligible patients will be approached at their acute admission (box 1 for inclusion criteria and box 2 for exclusion criteria).

\section{Randomisation and study blinding}

Patients will be randomised to receive sodium nitrite or matching placebo (in a 1:1 allocation) with both the patient and treating clinicians blinded to the assignment (double-blind). Manufacture of the investigational medicinal product, blinding, coding and randomisation will be carried out by the pharmacy manufacturing unit at Ipswich hospital prior to transfer of stock to the London Chest Hospital pharmacy. The randomisation list will be a computer-generated randomisation table (http://www. randomisation.com) based on blocks of ten to assign patients to treatment group or placebo group. Eighty indistinguishable vials of sodium nitrite and placebo will be provided and delivered to patients in a sequential fashion. Only the pharmacy at the London Chest Hospital and the manufacturing unit in Ipswich will be aware of the identity of the solution.

\section{Intervention}

The experimental intervention is a bolus of sodium nitrite solution, $1.8 \mu \mathrm{mol}$ in $10 \mathrm{ml}$ (prediluted in $0.9 \%$ sodium chloride in a syringe) which will be delivered over $30 \mathrm{~s}$ via intracoronary injection initiated during the re-establishment of antegrade epicardial flow with PPCI. The control intervention is a bolus of $0.9 \%$ sodium chloride solution (prepared with an identical appearance to the sodium nitrite). The patient, the PPCI operator and the assessor of clinical outcomes will be blinded to the treatment allocation.

After crossing the obstruction of the infarct-related coronary artery with a long guide wire, an over-the-wire balloon will be positioned at the level of the obstruction. The guide wire will then be removed and the sodium nitrite or placebo will be injected manually through the central lumen of the balloon catheter into the distal vascular bed over a period of $30 \mathrm{~s}$. The guide wire will then be reinserted through the balloon catheter and advanced to a distal position. The procedure will then be continued as per standard practice. The intracoronary route allows for the nitrite to be delivered in an adequately high and effective local concentration with negligible effects on systemic levels (owing to its uptake locally into ischaemic myocardium, short half-life of $\sim 1 \mathrm{~min}$ and systemic dilution). The dose of $1.8 \mu \mathrm{mol}$ is derived from clinical studies in human forearms where this dose resulted in a local concentration between 2.5 and $10 \mu \mathrm{mol} / \mathrm{l}$, well within the range associated with protection in reperfusion injury. ${ }^{46-48}$

\section{Study endpoints}

Blood samples for troponin-T and creatine kinase (CK) will be taken prior to PPCI and at 4, 8, 12, 18, 24, 36 and $48 \mathrm{~h}$ postprocedure. Blood sample for full blood 


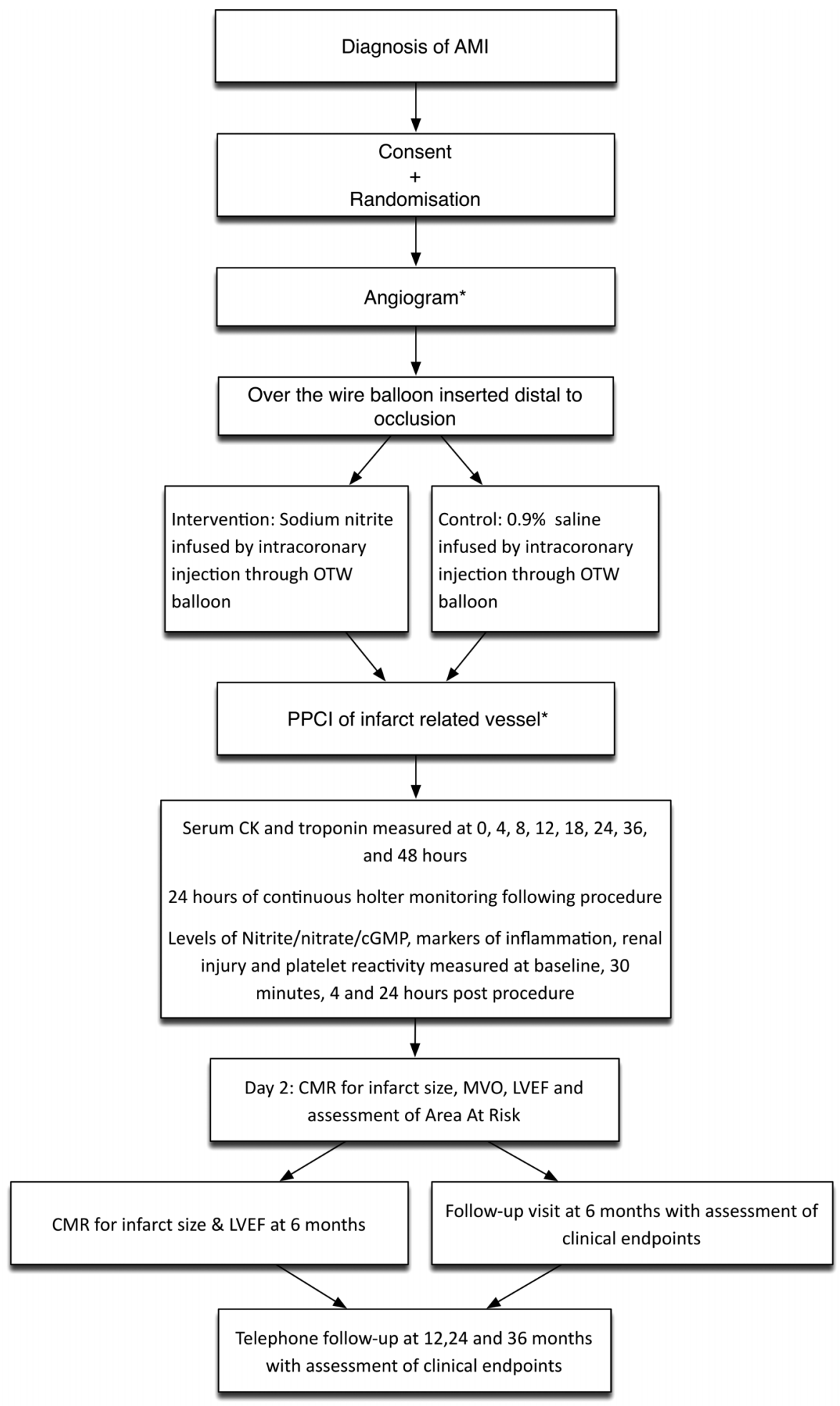

\section{AMI: acute myocardial infarction, OTW: Over the wire balloon, PPCl: primary percutaneous coronary intervention, CMR: cardiac magnetic resonance imaging, MVO: microvascular obstruction, LVEF: Left ventricular ejection fraction}

Figure 1 Flow diagram of study design.

count, urea and electrolytes, liver function tests, glycosylated hemoglobin, glucose, total cholesterol, will be taken at baseline. Arterial blood gases will be taken pre-PPCI and post-PPCI to assess levels of methaemoglobin. N-terminal pro-brain natriuretic peptide will be measured at baseline and $48 \mathrm{~h}$. Blood will be collected for flow cytometry assessment of inflammation and platelet reactivity at baseline, $30 \mathrm{~min}, 4$ and 


\section{Box 1 Inclusion criteria}

- Patients aged between 18 and 80 years

- Acute ST-elevation myocardial infarction with ECG showing ST-segment elevation of $1 \mathrm{~mm}$ or more in two adjacent limb leads or $2 \mathrm{~mm}$ or more in at least two contiguous precordial leads or new left bundle branch block

- Haemodynamically stable

- Estimated symptom to balloon or aspiration time $<6 \mathrm{~h}$

- Angiographically

- Primary percutaneous coronary intervention indicated for revascularisation

- Single epicardial artery to be treated

- Expected ability to use over the wire balloon

$24 \mathrm{~h}$ post-PPCI. Whole blood aggregometry will be used for assessment of platelet reactivity. Plasma nitrite, nitrate and cyclic guanosine monophosphatase (cGMP) (surrogate for NO) levels will be measured at baseline, postprocedure and at 4 , and $24 \mathrm{~h}$ post-PPCI. Cardiac MR (CMR) will be performed 2 days and 6 months after the index procedure.

\section{Box 2 Exclusion criteria}

- Inability to consent (including inability to speak English)

- Patients on organic nitrate treatment (nicorandil, isosorbide mononitrate)

- Previous history of acute myocardial infarction, systolic dysfunction or CABG

- Patients presenting with cardiogenic shock (systolic blood pressure $<80 \mathrm{~mm} \mathrm{Hg}$ for $>30 \mathrm{~min}$, or requiring inotropes or emergency intra aortic balloon pump for hypotension treatment) or cardiopulmonary resuscitation

- Current diagnosis of or treatment for malignancy, other than non-melanoma skin cancer

- Current life-threatening condition other than vascular disease that may prevent a patient from completing the study

- Use of an investigational device or investigational drug within 30 days or five half-lives (whichever is the longer) preceding the first dose of study medication

- Patients considered unsuitable to participate by the research team (eg, owing to medical reasons, laboratory abnormalities, or patient's unwillingness to comply with all study-related procedures)

- Severe acute infection, or significant trauma (burns, fractures)

- Pregnancy

- Contraindications to cardiac MR scanning

- Pacemakers, intracranial clips or other metal implants

- Claustrophobia

- Renal failure (eGFR, epidermal growth factor receptor $<30 \mathrm{~m} / \mathrm{min}$ )

- History of alcohol or drug abuse within the past 6 months

- History of congenital methaemoglobinaemia

- Angiographically

- Severe vessel tortuosity, diffuse disease or severe calcification is present which may impede successful delivery of the over the wire balloon
The primary endpoint is myocardial infarct size, assessed by $48 \mathrm{~h}$ area under the curve (AUC) plasma CK levels. CK AUC is a recognised accurate estimate of infarct size ${ }^{49} 50$ used in multiple previous studies assessing both thrombolytic ${ }^{51}$ and mechanical reperfusion. ${ }^{20}$ Secondary endpoints include alternative measures of myocardial infarct size $(48 \mathrm{~h}$ AUC troponin $\mathrm{T}$, CMR-determined infarct size, myocardial salvage index, $\mathrm{LV}$ volumes, mass and ejection fraction and the presence of microvascular obstruction (MVO)), and mechanistic endpoints (plasma nitrite/cGMP) concentrations/and markers of inflammation/platelet reactivity measured at baseline, post-procedure, at $4 \mathrm{~h}$ and $24 \mathrm{~h}$ post-PPCI). Clinical endpoints include the acute safety and tolerability of intracoronary nitrite in STEMI (haemodyamics and inpatient major adverse cardiac events (MACE)), assessment of ventricular rhythm disturbance for $24 \mathrm{~h}$ post-PPCI and an assessment of MACE endpoints at 6 and 12 months (death, heart failure, MI, stroke, need for repeat revascularisation).

\section{CMR imaging and analysis}

CMR imaging will be performed 2 days and 6 months \pm 2 weeks following study drug administration using a 1.5-T scanner (Philips Medical Systems, Best, the Netherlands). Each examination will use cine-CMR for ventricular volumes and function, and delayedenhancement CMR (DE-CMR) for infarct size assessment and evaluation of MVO. Myocardial oedema will be assessed at all time points using T2-weighted triple inversion turbo spin echo STIR imaging (TE 80, TR 1667). The inversion time will be optimised to null normal myocardium. Images will be anonymised, batched and analysed in a blinded fashion by two experienced operators. Scar and oedema volumes will be calculated by manually drawing endocardial and epicardial contours followed by semiautomated selection of normal remote myocardium per slice. Myocardial oedema will be described as $>2$ SD in signal intensity from remote normal myocardium. Infarct size will be calculated using the full-width half maximum method as previously described. $^{52}$

\section{Myocardial salvage index}

When assessing the efficacy of a reperfusion treatment strategy, it is essential to express myocardial infarct size (IS) as a percentage of the area-at-risk (AAR). In this study, the AAR will be quantified using both coronary angiography (modified Bypass Angioplasty Revascularisation Investigation (BARI) ${ }^{53}$ and modified Alberta Provincial Project for Outcome Assessment in Coronary Heart Disease $(\mathrm{APPROACH})^{54}$ jeopardy scores) and the acute (2 day) CMR scan (infarct endocardial-surface-area (Infarct-ESA)). As a measure of the AAR, infarct-ESA has been validated against the BARI and modified APPROACH scores ${ }^{54}$ and T2-weighted imaging of myocardial oedema. ${ }^{55}$ Myocardial salvage index will be calculated according to (AAR-IS) /AAR. 


\section{Adverse events reporting}

Safety analyses will summarise all adverse events (AEs), serious AEs and related unexpected serious AEs. The number of events and number of patients with events will be summarised. All serious adverse events (SAEs) that are thought to be related to treatment are subject to expedited reporting and will be reported within $24 \mathrm{~h}$ of study team becoming aware. The principal investigator will be responsible for follow-up of all SAEs to ensure all details are available and for reporting to the regulatory authorities.

\section{Statistical analysis}

To calculate the target sample size for the trial, we used the available database of the study of myocardial postconditioning by Staat $e t a{ }^{56}$ and a recent study assessing cyclosporine $^{11}$ for infarct size reduction. ${ }^{49}$ We hypothesised that nitrite would reduce the AUC for CK release by $30 \%$, the same amount as both cyclosporine and postconditioning. For a statistical power of $80 \%$ and a probability of a type I error of 0.05 using a two-sided test, we calculated that the sample size should be 70 patients (35 per group). Since 4$8 \%$ of patients will die by the time of the primary endpoint at 6 months and $10 \%$ will either not tolerate or fail to attend the MRI at 6 months an additional 10 patients will be needed, giving a total of 80 patients.

Analysis will be based on the intention-to-treat principle. Baseline demographic and clinical variables are summarised for each arm of the study. Descriptive summaries of the distributions of continuous baseline variables will be presented in terms of percentiles (eg, median, 25th and 75th percentile), while discrete variables will be summarised in terms of frequencies and percentages. The statistical comparisons of the treatment arms with respect to the primary endpoint will be performed using the Wilcoxon rank-sum test as the principal analytic tool. All $\mathrm{p}$ values will be two-sided. Comparisons will be between the sodium nitrite-treated and placebo control-treated group for the primary and secondary outcomes.

\section{Monitoring}

A trial steering committee composed of three independent experts in the fields of: pharmacology, interventional cardiology and clinical trials along with the investigators will monitor the study. This will include a lay member to focus on patient issues. This committee will meet before patient recruitment and then annually to assess safety, feasibility or any other arising problems (eg, with recruitment) and their recommendations will be followed. In addition an independent Data and Safety Monitoring Committee (DSMC) will monitor patients' safety and treatment efficacy data while the trial is ongoing. This committee is independent of the sponsor and investigators, and has no competing interests. The DSMC will meet prior to initiation of the clinical study, after the recruitment of 10 patients and then at 3 monthly intervals. The DSMC will have access to unblinded patient data. If a serious concern with the safety of the patients in the trial would arise, the DSMC may recommend early termination of the study.

\section{Ethical considerations and dissemination Ethical considerations}

The important ethical considerations concern (1) consent in the acute setting, (2) the risk of the intervention itself and (3) any delay in door to balloon time.

1. Seeking informed consent for clinical research from patients suffering from AMI is an ethical challenge owing to the medical condition of the patients, the emergency situation and the limited time available. There is no obvious solution to the particular difficulties of informed consent in this situation, and so previously patients have been enrolled in AMI trials on the basis of more or less comprehensive consent procedures. We have addressed this by excluding patients who are unconscious, critically unstable (cardiogenic shock) or deemed unable to consent (pain, distress, language) and by also providing a clear and concise summary sheet shown to the patient during the consent process.

2. The risks from the intervention are low. Sodium and nitrite are endogenously occurring ions with no immunological potential therefore there is no risk of an allergic reaction. The small volume of $1.8 \mu \mathrm{mol}$ in $10 \mathrm{ml}$ of saline given over $30 \mathrm{~s}$ is very unlikely to pose any problems.

3. The delivery of the intervention (sodium nitrite) down the coronary artery will lead to a small delay in balloon inflation, however any possible delay has been minimised by

A. the guide wire may have already restored some epicardial flow before the IMP is delivered

B. nitrite will be infused through an over-the-wire balloon which can be inflated immediately after infusion restoring flow, if necessary, otherwise an export catheter will be used to aspirate thrombus first

C. the time of the infusion has been kept to $30 \mathrm{~s}$ meaning at most there should be a delay of 1-2 min in the door to balloon time.

\section{Potential benefits}

If the impressive effect of sodium nitrite on reperfusion injury does translate from animal studies to humans, this would result in smaller infarcts and potentially better functional parameters in patients treated with nitrite. If this positive outcome occurs this would pave the way for the future development of this cheap and easily manufactured substance that could be made readily and widely available to the general population in the future.

\section{DISSEMINATION}

The study will be performed in agreement with the Declaration of Helsinki and is approved by the local 
ethics committee (NRES Committee London West London: 11/LO/1500). The study has also been approved by the Medicines and healthcare products Regulatory Agency (MHRA) (EudraCT nr. 2010-022460-12). Data collection will be completed by mid-2013. Primary and secondary analysis will start immediately after data monitoring is completed, publications will be prepared for submission in late 2013. The results of the trial will be published according to the CONSORT statement. Dissemination of results will focus on publications in peer-reviewed journals, presentations at national/international cardiology meetings and NHS groups. In accordance with recommendations, we have registered NITRITE-AMI with public registries, the UK Clinical Research Network (Study ID 12117), http://clinicaltrials.gov (NCT01584453) and Current Controlled Trials (International Standard Randomised Controlled Trials No: 38736987).

\section{SUMMARY}

Experimental studies in myocardial $\mathrm{I} / \mathrm{R}$ injury have demonstrated a protective effect of sodium nitrite but to date no clinical studies have been performed. The NITRITE-AMI study is a first-in-man study assessing the safety and efficacy of intracoronary nitrite infusion during acute myocardial infarction. The results of the study will set the stage for a larger trial to evaluate the safety and efficacy of sodium nitrite during STEMI.

Contributors All authors listed above fulfil all three International Committee of Medical Journal Editors (ICMJE) guidelines for authorship which are (1) substantial contributions to conception and design, acquisition of data or analysis and interpretation of data; (2) drafting the article or revising it critically for important intellectual content and (3) final approval of the version to be published. DAJ was responsible for coordinating the contribution of all authors to this paper. All authors made significant contributions to the development and conceptualisation of the protocol. DAJ, MA and SA were responsible for drafting this paper. AJW, RJS, AA and AM were responsible for editing and providing guidance on the paper. All authors were responsible for critically revising the paper. All authors approved the final version of this paper for submission.

Funding DAJ and this work are funded by an NIHR Doctoral Fellowship (DRF-2011-04-080).

Competing interests None.

Ethics approval NRES Committee London West London.

Provenance and peer review Not commissioned; internally peer reviewed.

\section{REFERENCES}

1. Lambert L, Brown K, Segal E, et al. Association between timeliness of reperfusion therapy and clinical outcomes in ST-elevation myocardial infarction. JAMA 2010;303:2148-55.

2. Berger PB, Ellis SG, Holmes Jr DR, et al. Relationship between delay in performing direct coronary angioplasty and early clinical outcome in patients with acute myocardial infarction. Results from the global use of strategies to open occluded arteries in acute coronary syndromes (GUSTO-Ilb) trial. Circulation 1999;100:14-20.

3. McNamara RL, Wang $\mathrm{Y}$, Herrin J, et al. Effect of door-to-balloon time on mortality in patients with ST-segment elevation myocardial infarction. J Am Coll Cardiol 2006;47:2180-6.

4. Cannon CP, Gibson CM, Lambrew CT, et al. Relationship of symptom-onset-to-balloon time and door-to-balloon time with mortality in patients undergoing angioplasty for acute myocardial infarction. JAMA 2000;283:2941-7.

5. Smith EJ, Mathur A. Rothman MT recent advances in primary percutaneous intervention for acute myocardial infarction. Heart 2005;91:1533-6.

6. Keeley EC, Boura JA, Grines CL. Primary angioplasty versus intravenous thrombolytic therapy for acute myocardial infarction: a quantitative review of 23 randomised trials. Lancet 2003;361:13-20.

7. Widimsky P, Wijns W, Fajadet J, et al. Reperfusion therapy for ST elevation acute myocardial infarction in Europe: description of the current situation in 30 countries. Eur Heart J 2010;31:943-57.

8. McAlister FA, Quan H, Fong A, et al. Effect of invasive coronary revascularization in acute myocardial infarction on subsequent death rate and frequency of chronic heart failure. $\mathrm{Am} \mathrm{J} \mathrm{Cardiol}$ 2008;102:1-5

9. Burns RJ, Gibbons RJ, Yi Q et al. The relationships of left ventricular ejection fraction, end-systolic volume index and infarct size to six-month mortality after hospital discharge following myocardial infarction treated by thrombolysis. J Am Coll Cardiol 2002;39:30-6

10. Wu E, Ortiz JT, Tejedor $\mathrm{P}$, et al. Infarct size by contrast enhanced cardiac magnetic resonance is a stronger predictor of outcomes than left ventricular ejection fraction or end-systolic volume index: prospective cohort study. Heart 2008;94:730-6.

11. Gibbons RJ, Valeti US, Araoz PA, et al. The quantification of infarct size. J Am Coll Cardiol 2004;44:1533-42.

12. Majidi M, Kosinski AS, Al-Khatib SM, et al. Reperfusion ventricular arrhythmia 'bursts' predict larger infarct size despite TIMI 3 flow restoration with primary angioplasty for anterior ST-elevation myocardial infarction. Eur Heart J 2009;30:757-64.

13. Timmer JR, Breet N, Svilaas T, et al. Predictors of ventricular tachyarrhythmia in high-risk myocardial infarction patients treated with primary coronary intervention. Neth Heart $J$ 2010;18:122-8.

14. Saia F, Grigioni F, Marzocchi A, et al. Management of acute left ventricular dysfunction after primary percutaneous coronary intervention for ST elevation acute myocardial infarction. Am Heart $J$ 2010;160:S16-21.

15. Carden DL, Granger DN. Pathophysiology of ischaemia-reperfusion injury. J Pathol 2000;190:255-66.

16. Yellon DM, Hausenloy DJ. Myocardial reperfusion injury. $N$ Eng J Med 2007;357:1121-35.

17. Burzotta F, De Vita M, Gu YL, et al. Clinical impact of thrombectomy in acute ST-elevation myocardial infarction: an individual patient-data pooled analysis of 11 trials. Eur Heart J 2009;30:2193-203.

18. Eshaghian S, Shah PK, Kaul S. Advances in antiplatelet treatment for acute coronary syndromes. Heart 2010;96:656-61.

19. Stone GW, Witzenbichler B, Guagliumi G, et al. Bivalirudin during primary $\mathrm{PCl}$ in acute myocardial infarction. $N$ Engl $\mathrm{J}$ Med 2008;358:2218-30.

20. Piot $\mathrm{C}$, Croisille $\mathrm{P}$, Staat $\mathrm{P}$, et al. Effect of cyclosporine on reperfusion injury in acute myocardial infarction. $N$ Engl J Med 2008;359:473-81.

21. Bryan NS, Fernandez BO, Bauer SM, et al. Nitrite is a signaling molecule and regulator of gene expression in mammalian tissues. Nat Chem Biol 2005;1:290-7.

22. Webb AJ, Patel N, Loukogeorgakis S, et al. Acute blood pressure lowering, vasoprotective, and antiplatelet properties of dietary nitrate via bioconversion to nitrite. Hypertension 2008;51:784-90.

23. Li H, Cui $\mathrm{H}$, Kundu TK, et al. Nitric oxide production from nitrite occurs primarily in tissues not in the blood. J Biol Chem 2008;283:17855-63.

24. Feelisch M, Fernandez BO, Bryan NS, et al. Tissue processing of nitrite in hypoxia an intricate interplay of nitric oxide-generating and-scavenging systems. J Biol Chem 2008;283:33927-34.

25. Lundberg JO, Weitzberg E, Gladwin MT. The nitrate-nitrite-nitric oxide pathway in physiology and therapeutics. Nat Rev Drug Discov 2008;7:156-67.

26. Mount PF, Kemp BE, Power DA. Regulation of endothelial and myocardial NO synthesis by multi-site eNOS phosphorylation. J Mol Cell Cardiol 2007;42:271-9.

27. Bredt DS. Nitric oxide signaling specificity-the heart of the problem J Cell Sci 2003;116:9-15.

28. Giraldez RR, Panda A, Xia Y, et al. Decreased nitric-oxide synthase activity causes impaired endothelium-dependent relaxation in the postischemic heart. J Biol Chem 1997;272:21420-6.

29. Bolli R. Cardioprotective function of inducible nitric oxide synthase and role of nitric oxide in myocardial ischemia and preconditioning: an overview of a decade of research. $J \mathrm{Mol}$ Cell Cardiol 2001;33:1897-918. 
30. Moens AL, Claeys MJ, Timmermans JP, et al. Myocardial ischemia/ reperfusion-injury, a clinical view on a complex pathophysiological process. Int J Cardiol 2005;100:179-90.

31. Johnson G III, Tsao PS, Lefer AM. Cardioprotective effects of authentic nitric oxide in myocardial ischemia with reperfusion. Crit Care Med 1991;19:244-52.

32. Kubes P, Suzuki M, Granger DN. Nitric oxide: an endogenous modulator of leukocyte adhesion. Proc Natl Acad Sci 1991;88:4651.

33. Ahluwalia A, Foster P, Scotland RS, et al. Antiinflammatory activity of soluble guanylate cyclase: cGMP-dependent down-regulation of P-selectin expression and leukocyte recruitment. Proc Natl Acad Sci USA 2004;101:1386-91.

34. Palazzo AJ, Jones SP, Girod WG, et al. Myocardial ischemiareperfusion injury in CD18- and ICAM-1-deficient mice. Am J Physiol 1998;275:H2300-7.

35. Jones SP, Bolli R. The ubiquitous role of nitric oxide in cardioprotection J Mol Cell Cardiol 2006;40:16-23.

36. Razavi HM, Hamilton JA, Feng Q. Modulation of apoptosis by nitric oxide: implications in myocardial ischemia and heart failure. Pharmacol Ther 2005;106:147-62.

37. Dorn GW. Novel pharmacotherapies to abrogate postinfarction ventricular remodeling. Natl Rev Cardiol 2009;6:283-91.

38. Webb A, et al. Reduction of nitrite to nitric oxide during ischemia protects against myocardial ischemia/reperfusion damage. Proc Natl Acad Sci USA 2004;101:13683-88.

39. Duranski MR, Greer JJ, Dejam A, et al. Cytoprotective effects of nitrite during in vivo ischemia-reperfusion of the heart and liver. J Clin Invest 2005;115:1232-40.

40. Pluta RM, Dejam A, Grimes G, et al. Nitrite infusions to prevent delayed cerebral vasospasm in a primate model of subarachnoid hemorrhage. JAMA 2005;293:1477-84.

41. Jung $\mathrm{KH}, \mathrm{Chu} \mathrm{K}, \mathrm{Ko} \mathrm{SY}$, et al. Early intravenous infusion of sodium nitrite protects brain against in vivo ischemia-reperfusion injury. Stroke 2006;37:2744-50.

42. Tripatara P, Patel NSA, Webb A, et al. Nitrite-derived nitric oxide protects the rat kidney against ischemia/reperfusion injury in vivo: role for xanthine oxidoreductase. J Am Soc Nephrol 2007;18:570-80.

43. Baker JE, Su J, Fu X, et al. Nitrite confers protection against myocardial infarction: role of xanthine oxidoreductase, NADPH oxidase and K(ATP) channels. J Mol Cell Cardiol 2007;43:437-44.

44. Hendgen-Cotta UB, Merx MW, Shiva S, et al. Nitrite reductase activity of myoglobin regulates respiration and cellular viability in myocardial ischemia-reperfusion injury. Proc Natl Acad Sci USA 2008;105:10256

45. Gonzalez FM, Shiva S, Vincent PS, et al. Nitrite anion provides potent cytoprotective and antiapoptotic effects as adjunctive therapy to reperfusion for acute myocardial infarction. Circulation 2008;117:2986-94

46. Cosby K, Partovi KS, Crawford JH, et al. Nitrite reduction to nitric oxide by deoxyhemoglobin vasodilates the human circulation. Nat Med 2003:9:1498-505.

47. Dejam A, Hunter CJ, Tremonti C, et al. Nitrite infusion in humans and nonhuman primates: endocrine effects, pharmacokinetics, and tolerance formation. Circulation 2007;116:1821-31.

48. Maher AR, Milsom AB, Gunaruwan P, et al. Hypoxic modulation of exogenous nitrite-induced vasodilation in humans. Circulation 2008;117:670-7.

49. Chia S, Senatore F, Raffel OC, et al. Utility of cardiac biomarkers in predicting infarct size, left ventricular function, and clinical outcome after primary percutaneous coronary intervention for ST-segment elevation myocardial infarction. JACC Cardiovasc Interv 2008;1:415-23.

50. Grande P, Christiansen C, Alstrup K. Comparison of ASAT, CK CK-MB, and LD for the estimation of acute myocardial infarct size in man. Clin Chim Acta 1983;128:329-35.

51. Turer AT, Mahaffey KW, Gallup D, et al. Enzyme estimates of infarct size correlate with functional and clinical outcomes in the setting of ST-segment elevation myocardial infarction. Curr Control Trials Cardiovasc Med 2005;6:12.

52. Flett AS, Hasleton J, Cook C, et al. Evaluation of techniques for the quantification of myocardial scar of differing etiology using cardiac magnetic resonance. JACC Cardiovasc Imaging 2011;4:150-6.

53. Alderman EL, Stadius M. The angiographie definitions of the bypass angioplasty revascularization investigation. Coron Artery Dis 1992;3:1189-208.

54. Ortiz-Perez JT, Meyers SN, Lee DC, et al. Angiographic estimates of myocardium at risk during acute myocardial infarction: validation study using cardiac magnetic resonance imaging. Eur Heart $J$ 2007;28:1750-8.

55. Wright J, Adriaenssens T, Dymarkowski S, et al. Quantification of myocardial area at risk with T2-weighted CMR: comparison with contrast-enhanced CMR and coronary angiography. JACC: Cardiovasc Imaging 2009;2:825-31.

56. Staat P, Rioufol G, Piot C, et al. Postconditioning the Human Heart. Circulation 2005;112:2143-8. 